\title{
Marco GUIGNI et Florence PASSY, La citoyenneté en débat. Mobilisations politiques en France et en Suisse
}

Caroline Rozenholc

\section{(2) OpenEdition \\ 12 Journals}

\section{Édition électronique}

URL : https://journals.openedition.org/remi/4229

DOI : $10.4000 /$ remi.4229

ISSN : $1777-5418$

Éditeur

Université de Poitiers

\section{Édition imprimée}

Date de publication : 1 décembre 2007

Pagination : 205-206

ISBN : 978-2-911627-47-4

ISSN : 0765-0752

\section{Référence électronique}

Caroline Rozenholc, « Marco GUIGNI et Florence PASSY, La citoyenneté en débat. Mobilisations politiques en France et en Suisse », Revue européenne des migrations internationales [En ligne], vol. 23 $n^{\circ} 3$ | 2007, mis en ligne le 27 novembre 2008, consulté le 15 avril 2022. URL : http:// journals.openedition.org/remi/4229; DOI : https://doi.org/10.4000/remi.4229

Ce document a été généré automatiquement le 15 avril 2022.

(c) Université de Poitiers 


\title{
Marco GUIGNI et Florence PASSY, La citoyenneté en débat. Mobilisations politiques en France et en Suisse
}

\author{
Caroline Rozenholc
}

\section{RÉFÉRENCE}

Marco GUIGNI et Florence PASSY, La citoyenneté en débat. Mobilisations politiques en France et en Suisse Paris, Éd. L'Harmattan, coll. Logiques Politiques, 2006, 301 p., ISBN :

978-2-7475-9787-6

1 Quels défis les migrants posent-ils à leur pays d'accueil ? En quoi l'immigration et les relations interethniques constituent, à la fois, une politique contestataire et une politique contestée? Comment expliquer les différences notoires de gestions migratoires entre pays européens, par exemple? Quels sont les modes d'organisation de l'action protestataire dans le domaine des relations interethniques? La citoyenneté en débat répond à toutes ces questions en multipliant les points de comparaison entre deux contextes nationaux proches : la France et la Suisse. En sept chapitres et quelques annexes méthodologiques, M. Guigni et F. Passy déroulent méticuleusement leur réflexion. Et défont certaines idées largement partagées quant aux délitements de l'État-nation ou aux modalités de résurgence de l'extrême droite. En analysant la prise de parole publique des acteurs sur les enjeux migratoires pendant les années quatrevingt-dix, période où la question migratoire s'est largement politisée, les auteurs créent des indicateurs qui permettent d'évaluer les conceptions collectives de la citoyenneté. Leurs analyses empiriques s'appuient sur les revendications publiques dans trois domaines: les politiques d'immigration et d'asile, la politique d'intégration des migrants et des minorités ethniques, le domaine du racisme et de l'anti-racisme.

2 Pour comprendre les dynamiques qui régissent ces champs d'action, les auteurs analysent chacune des deux dimensions de la citoyenneté en France et en Suisse : les 
accès individuels - via les statuts de résidence, les modalités du regroupement familial et les conditions d'expulsion des migrants - et collectifs à la citoyenneté. Il apparaît alors que l'accès individuel à la nation, le premier pilier de la citoyenneté, est le plus aisé. Alors que l'accès collectif à l'espace national touche, quant à lui, aux «identités constitutives" même des citoyen-ne-s. Toute revendication d'élargissement de cet espace culturel est donc des plus délicate. Mais la simple présence des migrants sur le territoire national est à la fois une demande d'ouverture de l'espace physique de la nation, de ses frontières, et l'ouverture de l'espace culturel de la nation. De la reconnaissance de droits de la personne à la volonté explicite de promouvoir des droits spéciaux pour certaines communautés, les revendications - même silencieuses - des migrants touchent donc au cœur les démocraties libérales. Elles remettent en question un des principes constitutifs des États libéraux; des États qui reposent sur des logiques individuelles. D'où l'impossibilité de formuler en France des mesures de discriminations positives, qui seraient des mesures collectives et distinctives. L'ouvrage égrène d'autres « rappels » qui pourraient sembler anecdotiques mais qui, en réalité, sont révélateurs des enjeux de ces débats : en France, plus de la moitié des défunts musulmans sont rapatriés dans leur pays d'origine pour y être enterrés selon les pratiques coraniques; la polygamie est formellement interdite et peut entraîner l'expulsion du territoire ; en Suisse, alors que l'abattage rituel faisait récemment débat et éveillait les oppositions des défenseurs des droits des animaux, son interdiction en 1882 visait ouvertement à contrarier les pratiques religieuses juives; et dans les deux pays, le secteur public est pour l'heure réservé aux nationaux.

Des conclusions et des a priori que cet ouvrage bouscule, on retiendra aussi la proposition d'ouvrir l'arène politique conventionnelle aux partis de la droite radicale pour en voir diminuer la violence. Les auteurs montrent bien que la résurgence de l'extrême droite en Europe occidentale ne reflète ni la présence de griefs au sein de la population ni la compétition entre groupes ethniques pour l'accès aux ressources. De manière tout à fait intéressante, l'ouvrage suggère que ces réponses politiques proviennent des ressources culturelles de la nation, qu'elles sont puisées dans des opportunités politiques déjà existantes. Au final, et c'est l'enjeu de ce livre, seule la mise en perspective entre contextes nationaux proches est à même de faire apparaître des compréhensions différentes de la citoyenneté. La comparaison permet également de montrer à quel point ces compréhensions sont essentielles dans les débats sur la question de l'immigration. Elles en constituent un des éléments les plus structurants. Si le domaine des migrations est un champ politique contesté s'est donc aussi parce que s'y «affrontent» des imaginaires de citoyenneté différents. Des conceptions concurrentielles et souvent contradictoires. Les âpres débats de ces dernières années prennent avec cet ouvrage une nouvelle dimension puisque l'immigration et l'intégration sont abordées par le biais des imaginaires de la nation et de la citoyenneté; et de l'impact de ceux-ci sur les politiques migratoires d'aujourd'hui. L'histoire de chaque pays, de chaque État, constitue le «cadre d'opportunités et de contraintes " pour les acteurs politiques engagés dans ces questions. Elle dessine aussi la place que les États accordent aux identités plurielles. En dépit des thèses postnationa-listes, l'État-nation constitue encore « l'acteur le plus engagé » dans les débats publics sur les questions migratoires. L'acquisition des droits de citoyenneté demeure une dimension essentielle d'inclusion et d'exclusion des migrants. La citoyenneté en débat remet donc l'État au cœur des discussions sur les questions d'immigration et de relations interethniques. 
4 L'intérêt de cet ouvrage est donc de proposer un cadre théorique et méthodologique qui permette de penser les positions et revendications politiques dans le champ des migrations comme un continuum; des mobilisations de l'extrême droite aux revendications des acteurs anti-racistes. Mais il permet aussi de pointer les mécanismes qui empêchent, par exemple, les acteurs politiques en France d'entrer dans l'espace public en mobilisant des identités particulières, ethniques ou religieuses. Et les difficultés de la Suisse à se reconnaître comme pays d'immigration (le principe de double nationalité n'a été accepté en Suisse qu'en 1992). Finalement, pour reprendre la question de départ, c'est donc surtout en ce qu'elle mobilise et éveille des « imaginaires opposés et contradictoires " à l'égard de la nation que la " présence étrangère » est un défi aux démocraties occidentales libérales. Ce sont bien les États qui façonnent les possibilités pour les non-citoyens d'entrer dans l'espace public. De manière inattendue, cette analyse de la mobilisation des populations migrantes en France et en Suisse vient donc pondérer le discours sur le trans-nationalisme généralisé. Mais face à la multiplication "des identités plurielles dans l'espace public et dans les institutions » comment se formulent les identités locales? Peuvent-elles venir moduler les conceptions nationales de citoyenneté ? Le « peuple prend-il le pas sur le citoyen »?

\section{AUTEURS}

\section{CAROLINE ROZENHOLC}

Doctorante, Université de Poitiers-Migrinter 